\title{
The Rate of Mandibular Incisor Initial Alignment and Occlusal Dimensional Changes: A Comparison between Conventional and Self-Ligating Brackets
}

\section{Ferdinand Mabula Machibya ${ }^{1 *}$, Deng Wenwen ${ }^{2}$}

${ }^{1 *}$ DClinDent, Muhimbili University of Health and Allied Sciences, School of Dentistry, Tanzania. ${ }^{2} \mathrm{MDM}$, Jilin University, College of Stomatology, China.

frmachibya@yahoo.com

*Corresponding Author: Dr. Ferdinand M Machibya, Department of Orthodontics, Pedodontics and Community Dentistry, Muhimbili University of Health and Allied Sciences, Tanzania.

Abstract

Introduction: Self-ligating brackets (SLBS) are considered to have several advantages over conventional brackets (CBs). However some of their strengths lack support by strong clinical studies.

Aim: To compare the rate of mandibular incisor initial alignment and occlusal dimensional changes among none-extraction patients treated with conventional (Victory Series) and self-ligating (SmartClip) brackets.

Material and Methods: Fifty-seven patients (30 SLB and 27 CB) were enrolled to investigate the rate of incisors alignment and occlusal dimensional changes. The Little irregularity index measured on dental models used to quantify the amount of dental discrepancy before (T1) and after (T2) alignment of the anterior dentition. The time taken to align the irregularity was as well measured to determine the rate of teeth alignment. In addition, the inter-canines and inter-molars distances were measured on dental models at T1 and T2 to assess the arch dimension changes

Results: The total mean (maxillary and Mandibular) discrepancies reductions were 6.66-mm (SLB) and 8.04$\mathrm{mm}(C B)$. Whereas, the time used for incisors alignment by SLB and CB groups were 93.48 and 93.38 days respectively. The occlusal changes and rate of. The mean Little's index reduction ( $\mathrm{mm} / \mathrm{month})$ was 2.05 for $S L B$ and 2.43 for CB groups. The difference was not statistically significant $(P=0.216)$

Conclusion: The rate of incisors alignment was not influenced by the type of bracket used. The alignment significantly increased the inter-canine and inter-molar distances except for maxillary inter-canines distance; however the arch dimension measurements were independent of the bracket systems used

Keywords: Orthodontics, Self-ligating brackets, Dental alignment, Inter-canine distance, Inter-molar distance

\section{INTRODUCTION}

Self-ligating brackets (SLBs) with several supposed advantages over conventional brackets (CBs) are recently popular in orthodontic clinics worldwide. A significant amount of patients are being treated with self-ligating brackets according to report by orthodontists in America. ${ }^{1}$ The reported advantages of SLBs over CBs include greater patient comfort during treatment, better oral hygiene, increased patient cooperation, more certain archwire engagement, fewer visits to orthodontists, overall shorter treatment time, improved anchorage stability, less need for extractions, and better outcomes in term of occlusal and facial esthetics. ${ }^{2-4}$

Self-ligating bracket system is one of the scientific innovations in attempt to maximize patient treatment efficiency and effectiveness in orthodontics. ${ }^{5,6}$

Secure engagement of the main archwire into bracket is produced by a clip mechanism with self-ligating or stainless steel/elastomeric ligatures for the conventional brackets. Several self-ligating appliances with different mechanisms of slot closure have been 
The Rate of Mandibular Incisor Initial Alignment and Occlusal Dimensional Changes: A Comparison between Conventional and Self-Ligating Brackets

introduced to allow for efficient sliding mechanics by lowering force required for tooth movement owing to reduced friction and absence of ligatures bind on archwires. $^{7}$ The Damon, Time, Speed, SmartClip, and In-Ovation R are some of the popular SLBs currently in use.

\section{Classification of Self-Ligating Brackets:}

SLBs can be classified into passive and active designs based on the mode in which they interact with the archwire. The active type have a spring clip that encroaches on the slot from the labial/buccal aspect and presses against the archwire providing an active seatingforce on thearchwireand ensureengagement.In the passive type such as Damon (Ormco/"A"Company) and SmartClip ${ }^{\mathrm{TM}}$ (3M Unitek, USA) the clip does not press against the archwire. Instead, these brackets use a rigid door or latch to entrap the archwire providing more room for the archwire. ${ }^{8,9}$

Passive SLBs have shown consistently less friction during sliding mechanics than active SLBs, with the exception of undersized round arch wires. ${ }^{10,11}$

Most of the SLBs advantages are supported to a great extent by empirical and anecdotal evidence.,12 Sound scientific evidence from clinical trials is needed to support the reported SLBs superiority. Unfortunately, the evidence for most claims is lacking. ${ }^{[13]}$

It is speculated that, the use of passive SLB (Damon system) facilitates biologically sensible forces which work with the body's natural adaptive processes to create space naturally, thus most cases can be treated without extraction or need for headgear and palatal expanders. In a study by Yu et $\mathrm{al}^{13}$ the post treatment CT images were reported to show transverse arch development and normal alveolar bone on lingual and buccal surfaces. Low friction forces are purported to be good for physiologically rebuilding the alveolar bone. ${ }^{13}$ Due to environmental differences between in vitro and in vivo conditions; applying the results from in-vitro studies to clinical situations needs more clinical trial evidences.

Well-designed clinicaltrials with strictselection criteria are the only ways to ascertain some of the empirically proposed advantages of SLBs in clinical practice and facilitate informed treatment choices among patients. Hence, the aim of the current study was to compare the rate of mandibular incisor initial alignment and occlusal dimensional changes among none-extraction patients treated with conventional (Victory Series) and self-ligating (SmartClip) brackets.

\section{Materials ANd Methods}

The ethical approval for the study was obtained from the Jilin University Scientific committee.

\section{Selection of Subjects}

Fifty-seven patients were enrolled to investigate the rate of incisors alignment and occlusal dimensional changes. The SLB comprised of 30 participants whereas the CB included 27 patients. The participants were conveniently allocated to the respective type of bracket.

\section{Inclusion Criteria}

The following were criteria set for inclusion: Noneextraction treatment, no missing teeth, subjects with permanent dentition, no systemic or local disease which may impair treatment progress,

No spaces in arches, No previous orthodontic or orthognathic treatment; and no additional orthodontic appliances during alignment stage.

\section{Exclusion Criteria}

The participants were excluded on the following grounds: Unclear canines' cusps or first molar central fossae, use of additional orthodontic appliances (mini-implant, head gear, lingual arch, inter-maxillary elastics or any removable appliances) and missing three or more appointments during alignment stage.

The following arch-wire sequence was used in both groups during alignment stage: NiTi 0.012-in, 0.014 and 0.016 and the participants were reviewed on monthly appointments. The early alignment stage was completed and an impression for the second cast model (T2) was taken immediately before progressing from NiTi 0.016 -in to $0.016 \times 0.022$. The alignment completion $\mathrm{T} 2$ was clinically determined assisted by complete passive NiTi 0.016 archwire engagement assessed by tactile feeling.

\section{Dental Cast Models Analysis}

The Little irregularity index ${ }^{14}$ was used to quantify the amount of crowding of the anterior dentition. In addition, the inter-canines and inter-molars distances were measured on upper and lower jaws. 
The Rate of Mandibular Incisor Initial Alignment and Occlusal Dimensional Changes: A Comparison between Conventional and Self-Ligating Brackets

The reference points were the cusps and central fossae on canines and first molars respectively. The measurements were done twice on the initial (T1) and after alignment (T2) casts by a vernier caliper

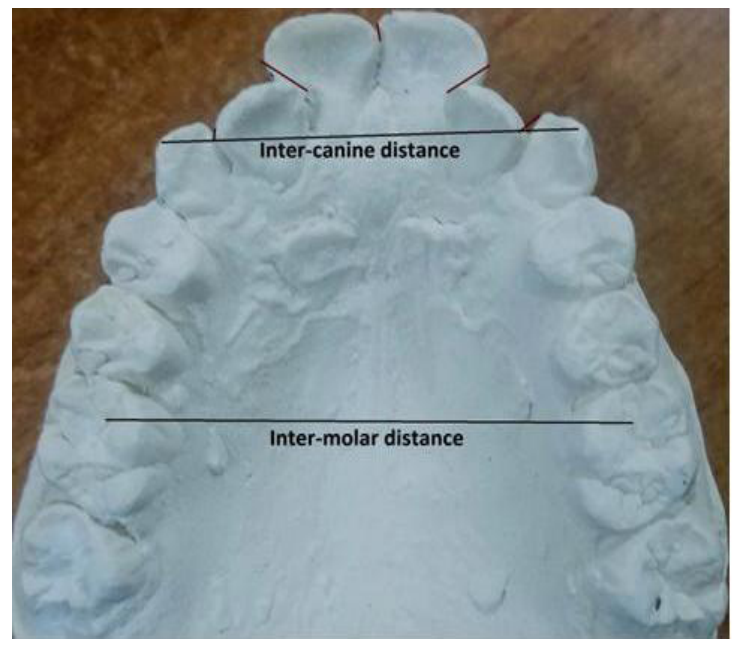

Before alignment
(Dentaurum, Germany) (Figure1). The averages of the two measurements were recorded for data analysis. The time (days) required to complete alignment (T2 - T1) was calculated for each patient.

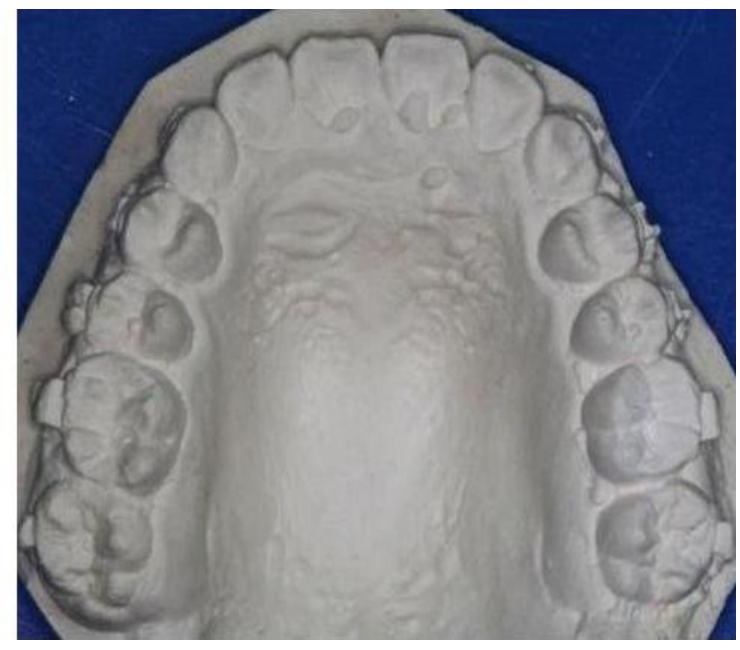

After alignment

Figure 1. Little's Irregularity Index (LII) and arch dimension measurement

\section{Statistical Analysis}

Descriptive and analytical statistical analyses were performed with SPSS for Windows, version 13.0 software (SPSS Inc, Chicago, Illinois). The data showed a normal distribution tendency; hence we applied parametric statistical analysis, with level of statistical significance set at $\mathrm{P}<0.05$.

The independent sample Student's $t$-test was used to detect significant differences between mean scores of SLB and CB Little's index and arch dimensional changes after treatment.

To test the examiner's accuracy and consistency in evaluating the study models, thirty dental cast models were randomly selected and measured twice at the interval of two weeks to obtain two sets of data. The paired sample $t$ test showed no significant mean differences between the two series of records, with a method error of less than $0.5 \mathrm{~mm}$.

\section{RESULTS}

\section{Sample Demographic Information}

Fifty-seven patients were enrolled to investigate the rate of incisors alignment and occlusal dimensional changes. Table 1 shows the sample demographic distribution. There was no statistically differences in participants' distribution between SLB and CB groups regarding age $(\mathrm{P}=.44)$, sex $(\mathrm{P}=.38)$ and Little's discrepancy index score before treatment $(\mathrm{P}=0.25)$

Table 1. The participants' demographics distribution according to types of brackets.

\begin{tabular}{|l|l|l|l|}
\hline Variable & SLB & CB & Total \\
\hline Patients age Mean (STD) & $13.73(3.41)$ & $14.55(3.36)$ & $13.89(3.53)$ \\
\hline Male N (\%) & $11(19.3)$ & $11(19.3)$ & $22(38.6)$ \\
\hline Female N (\%) & $19(33.33)$ & $16(28.07)$ & $35(61.4)$ \\
\hline Total N (\%) & $30(52.63)$ & $27(47.37)$ & $57(100)$ \\
\hline
\end{tabular}

The paired samples t-test compared the Little's score and occlusal dimensional changes before and after treatment (Tables 2 and 3). With exception of maxillary inter-canine diameter, all measurements in table 2 were statistically significantly different when compared before and after treatment, regardless of the type of brackets used. 
The Rate of Mandibular Incisor Initial Alignment and Occlusal Dimensional Changes: A Comparison between Conventional and Self-Ligating Brackets

Table 2. The Arch dimensional and Little's index mean score: paired sample t test (T1-T2)

\begin{tabular}{|c|c|c|c|}
\hline Paired variables & Mean (Std) & Mean difference (T1-T2) & P Value \\
\hline Maxillary inter-canine diameter T1 & $34.45(3.083)$ & \multirow{2}{*}{$-0.54(2.07)$} & \multirow{2}{*}{0.086} \\
\hline Maxillary inter-canine diameter T2 & $34.99(3.24)$ & & \\
\hline Maxillary inter-molar diameter T1 & $48.11(2.83)$ & \multirow{2}{*}{$-0.50(1.34)$} & \multirow{2}{*}{0.016} \\
\hline Maxillary inter-molar diameter T2 & $48.61(3.04)$ & & \\
\hline Mandibular inter-canine diameter T1 & $27.41(1.19)$ & \multirow{2}{*}{$-0.81(1.13)$} & \multirow{2}{*}{0.00} \\
\hline Mandibular inter-canine diameter T2 & $28.22(1.68)$ & & \\
\hline Mandibular inter-molar diameter T1 & $43.28(2.69)$ & \multirow{2}{*}{$-0.46(1.24)$} & \multirow{2}{*}{0.016} \\
\hline Mandibular inter-molar diameter T2 & $43.74(3.15)$ & & \\
\hline Maxillary Little's index score T1 & $10.46(3.99)$ & \multirow{2}{*}{$9.69(4.24)$} & \multirow{2}{*}{0.00} \\
\hline Maxillary Little's index score T2 & $0.77(1.40)$ & & \\
\hline Mandibular Little's index score T1 & $5.56(4.10)$ & \multirow{2}{*}{$4.72(4.13)$} & \multirow{2}{*}{0.00} \\
\hline Mandibular Little's index score T2 & $0.84(1.46)$ & & \\
\hline
\end{tabular}

The total mean (maxillary and Mandibular) of Little's index reduction between the SLB and CB discrepancies reductions were 6.66-mm (SLB) and 8.04-mm (CB). Whereas, the time used for incisors alignment by SLB and CB groups were 93.48 and 93.38 days respectively. The occlusal changes and rate groups were not statistically significant (Table 4). The mean Little's index reduction (mm/month) was 2.05 for SLB and 2.43 for CB groups. The difference was not statistically significant $(\mathrm{P}=0.216)$

Table 4. Mean comparison of arch dimension, Little's Index score Changes (before and after treatment) and rate of alignment. By independent sample t test.

\begin{tabular}{|c|c|c|c|c|c|}
\hline & & & \multicolumn{2}{|c|}{ 95\% C I for Mean } & \multirow[b]{2}{*}{$\mathbf{P}$} \\
\hline & & Mean (Std) & Lower & Upper & \\
\hline \multicolumn{6}{|c|}{ Arch dimension Changes before and after treatment (mm) } \\
\hline \multirow{3}{*}{ Maxillary inter-canine } & SLB & $0.47(2.50)$ & -0.52 & 1.46 & \multirow{3}{*}{0.791} \\
\hline & CB & $0.64(1.23)$ & 0.03 & 1.26 & \\
\hline & Total & $0.54(2.07)$ & -0.08 & 1.16 & \\
\hline \multirow{3}{*}{ Maxillary inter-molar } & SLB & $0.74(1.41)$ & 0.18 & 1.3 & \multirow{3}{*}{0.142} \\
\hline & CB & $0.14(1.18)$ & -0.45 & 0.73 & \\
\hline & Total & $0.50(1.34)$ & 0.1 & 0.9 & \\
\hline \multirow{3}{*}{ Mandibular inter-canine } & SLB & $0.93(0.98)$ & 0.54 & 1.32 & \multirow{3}{*}{0.37} \\
\hline & CB & $0.62(1.32)$ & -0.03 & 1.28 & \\
\hline & Total & $0.81(1.13)$ & 0.47 & 1.15 & \\
\hline \multirow{3}{*}{ Mandibular inter-molar } & SLB & $0.30(0.97)$ & -0.08 & 0.69 & \multirow{3}{*}{0.305} \\
\hline & CB & $0.69(1.56)$ & -0.08 & 1.47 & \\
\hline & Total & $0.46(1.24)$ & 0.09 & 0.83 & \\
\hline \multicolumn{6}{|c|}{ Changes in Little's Index score (mm) } \\
\hline \multirow{3}{*}{ Maxillary Little's index score } & SLB & $9.40(4.33)$ & 7.69 & 11.11 & \multirow{3}{*}{0.581} \\
\hline & CB & $10.13(4.19)$ & 8.04 & 12.21 & \\
\hline & Total & $9.69(4.24)$ & 8.41 & 10.97 & \\
\hline \multirow{3}{*}{ Mandibular Little's index score } & SLB & $3.91(4.16)$ & 2.26 & 5.55 & \multirow{3}{*}{0.106} \\
\hline & $\mathrm{CB}$ & $5.94(3.87)$ & 4.02 & 7.87 & \\
\hline & Total & $4.72(4.13)$ & 3.48 & 5.96 & \\
\hline \multicolumn{6}{|c|}{ Rate of alignment (Little's index reduction (mm/month) } \\
\hline \multirow{3}{*}{ Rate of alignment } & SLB & $2.05(1.13)$ & 1.6 & 2.5 & \multirow{3}{*}{0.216} \\
\hline & $\mathrm{CB}$ & $2.43(0.72)$ & 1.07 & 2.79 & \\
\hline & Total & $2.20(0.99)$ & 1,90 & 2.5 & \\
\hline
\end{tabular}


The Rate of Mandibular Incisor Initial Alignment and Occlusal Dimensional Changes: A Comparison between Conventional and Self-Ligating Brackets

\section{DISCUSSION}

Self-ligating brackets have eliminated some utilities or materials such as elastomeric modules and ligation wires along with the potential annoyances and tools associated with their application. The innovation is said to have several advantages including less chairside assistance, certain full archwire engagement, faster archwire removal/placement and low friction between bracket and archwire. ${ }^{15}$ However, there are inconsistent findings on some advantages. ${ }^{15,16}$ The bracket ligation systems advantages described in experimental studies are expected to affect the treatment efficacy and efficiency of particular bracket system in clinical situation. However, mindful of the environmental difference between oral cavity and invitro experimental situations, further clinical studies are required to ascertain the experimental findings in practices.

Wire dimension (size), inter-bracket distance, bracket composition, saliva lubrication, wire material, torque at the wire-bracket interface, angulation, ligation forces, bracket width and slot size are some of the factors reported to influence frictional force in edgewise appliances. ${ }^{17,18}$

Rinchuse et. $\mathrm{al}^{9}$ proposed the use of passive SLBs with low frictional force during initial alignment stages of treatment, and the active SLBs later in treatment for better three-dimensional control of teeth movement.

In the current study, the SLBs and CBs were found to be equally efficient in resolving incisors malalignment during early stage of orthodontic treatment. The mean difference in the rate of Little's index reduction was not statistically significant (Table 4). Typically, SLBs required 93.48 days to resolve 6.66- $\mathrm{mm}$ while CBs used 93.38 days for 8.04-mm incisors discrepancy. This gave the clinically and statistically insignificant group difference of $0.38 \mathrm{~mm}$ per month regarding the rate of incisors alignment, with CBs having relatively faster rate of alignment. The tight ligation in CBs may speed up the alignment compared to the passive SLBs due to the small size archwires used during alignment.

Despite the reported passive SLBs low resistance to sliding, this clinical trial has found no significant difference in the rate of alignment between SLB and
CB brackets, possibly due to the multiple factors influencing orthodontic treatment on clinical reality compared to experimental studies. Comparative findings have been reported by previous clinical trials. ${ }^{19,20}$ This emphasizes the need for clinical studies before inferring experimental study reports into clinical practices.

Although SLBs are thought to facilitate more nonextraction treatment by space creation through arch expansion, ${ }^{21}$ The current study on arch dimensional changes after alignment did not find significant differences between the bracket groups in regard to inter-canine and inter-molar distances (Table 4). However, with exception of maxillary inter-canines distance, the arch dimension measurements between $\mathrm{T} 1$ and T2 were statistically significantly different regardless of the bracket systems used (Table 2). Our findings are consistent with previous studies.,22,23 Scott et $\mathrm{al}^{22}$ found the changes to be independent of the bracket types. However, they speculated that the dimensional changes were associated with the type of patients enrolled in the study (i.e. Different trend in dimensional changes may be expected between extraction and non-extraction patients). In the current study, the inter-canines and inter-molars distance increased at T2 (Table2). Nonetheless, the difference in maxillary inter-canines was not statistically significant. The plausible explanation may be that the spaces for incisors alignment in the non-extraction patients were achieved through labial/buccal proclination of teeth and dimension expansion by the pre-formed NiTi archwires. The study did not find any evidence of the said SLBs advantage of physiological expansion of dental arches during alignment stage. The two bracket systems can therefore be treated equally on this aspect.

\section{ConCLUSIONS}

The findings in this study show that the time required for incisors alignment is not influenced by the type of bracket used. The alignment stage significantly increased the inter-canine and inter-molar distances except for maxillary inter-canines distance; however the arch dimension measurements were independent of the bracket systems used 
The Rate of Mandibular Incisor Initial Alignment and Occlusal Dimensional Changes: A Comparison between Conventional and Self-Ligating Brackets

\section{REFERENCES}

[1] Prettyman C, Best AM, Lindauer SJ, Tufekci E. Self-ligating vs conventional brackets as perceived by orthodontists. Angle Orthod. 2012;82(6):1060-6.

[2] Harradine NW. Self-ligating brackets: where are we now J Orthod 2003;30:262-73.

[3] Shivapuja PK, Berger J. A comparative study of conventional ligation and self-ligation bracket systems. Am J Orthod Dentofacial Orthop 1994; 106:472-80.

[4] Loh KW. Rapid tooth movement with a low-force, low-friction bracket system. J Clin Orthod 2007; 41:451-7.

[5] Skidmore KJ, Brook KJ, Thomson WM, Harding WJ. Factors influencing treatment time in orthodontic patients. Am J Orthod Dentofacial Orthop 2006;129:230-8.

[6] Teh LH,Kerr WJ,McColl JH. Orthodontic treatment with fixed appliances in the General Dental Service in Scotland. J Orthod 2000;27:175-80.

[7] Pandis N, Polychronopoulou A, Eliades T. Active or passive self-ligating brackets? A randomized controlled trial of comparative efficiency in resolving maxillary anterior crowding in adolescents Am J Orthod Dentofacial Orthop 2010;137:12.e1-12.e6.

[8] Maen Zreaqat and Rozita Hassan. Self-Ligating Brackets: An Overview. www.intechopen.com [accessed 02/02/2018]

[9] Rinchuse DJ, Miles PG. Self-ligating brackets: present and future. Am J Orthod Dentofacial Orthop. 2007;132(2):216-22.

[10] Pizzoni L, Ravnholt G, Melsen B. Frictional forces related to self-ligating brackets. Eur J Orthod 1998;20:283-91.

[11] Thomas S, Sherriff M, Birnie D. A comparative in vitro study of the frictional characteristics of two types of self-ligating brackets and two types of pre-adjusted edgewise brackets tied with elastomeric ligatures. Eur J Orthod 1998;20:589-96.

[12] Damon DH. The Damon low friction bracket: a biologically compatible straight-wire system. J Clin Orthod 1998;32:670-680.

[13] Yu YL, Qian YF. The clinical implication of selfligating brackets. Shanghai Kou Qiang Yi Xue. 2007;16(4):431-5.

[14] Little RM. The irregularity index: a quantitative score of Mandibular anterior alignment. Am J Orthod 1975;68:554-63.

[15] Eberting JJ, Straja SR, Tuncay OC. Treatment time, outcome, and patient satisfaction comparisons of Damon and conventional brackets. Clin Orthod Res 2001; 4:228-34.

[16] Harradine NW. Self-ligating brackets and treatment efficiency. Clin Orthod Res. 2001;4:220-7.

[17] Henao SP, Kusy RP. Evaluation of the frictional resistance of conventional and self-ligating bracket designs using standardized archwires and dental typodonts. Angle Orthod 2004;74:20211.

[18] Kapila S, Angolkar PV, Duncanson MG, Nanda RS. Evaluation of friction between edgewise stainless steel brackets and orthodonticwires of four alloys. Am J Orthod Dentofacial Orthop 1990;98:117-26.

[19] Ong E, McCallum H, Griffin M P, Christopher H. Efficiency of self-ligating vs conventionally ligated brackets during initial alignment Am J Orthod Dentofacial Orthop 2010;138:138.e1138. e7.

[20] Pandis N, Polychronopoulou A, Eliades T. Selfligating vs conventional brackets in the treatment of mandibular crowding: a prospective clinical trial of treatment duration and dental effects. Am J Orthod Dentofacial Orthop 2007;132:208-15.

[21] Harradine N, Bimie D. Self-ligating brackets: Theory and practice. www.scribd.com [accessed on 21/02/2018] 
The Rate of Mandibular Incisor Initial Alignment and Occlusal Dimensional Changes: A Comparison between Conventional and Self-Ligating Brackets

[22] Scott P, DiBiase AT, Sherriff M, Cobourne MT. Alignment efficiency of Damon3 self-ligating

[23] Jiang RP, Fu MK. Non-extraction treatment with and conventional orthodontic bracket systems: a self-ligating and conventional brackets. Zhonghua randomized clinical trial. Am J Orthod Dentofacial Kou Qiang Yi Xue Za Zhi 2008;43:459-63.

Orthop 2008;134:470:e1-8.

Citation: Ferdinand Mabula Machibya, Deng Wenwen. The Rate of Mandibular Incisor Initial Alignment and Occlusal Dimensional Changes: A Comparison between Conventional and Self-Ligating Brackets. Archives of Dentistry and Oral Health. 2018; 1(2): 06-12.

Copyright: (c) 2018 Ferdinand Mabula Machibya, Deng Wenwen. This is an open access article distributed under the Creative Commons Attribution License, which permits unrestricted use, distribution, and reproduction in any medium, provided the original work is properly cited. 